\title{
Role of partogram in the management of spontaneous labour in primigravida and multigravida
}

\section{Kavya Mahesh Penumadu*, C. Hariharan}

Department of Obstetrics \& Gynaecology, Datta Meghe Institute of Medical Sciences, Sawangi (Meghe), Wardha, Maharashtra, India

Received: 16 October 2014

Accepted: 1 November 2014

\section{*Correspondence:}

Dr. Kavya Mahesh Penumadu,

E-mail: kavya.penumadu@gmail.com

Copyright: () the author(s), publisher and licensee Medip Academy. This is an open-access article distributed under the terms of the Creative Commons Attribution Non-Commercial License, which permits unrestricted non-commercial use, distribution, and reproduction in any medium, provided the original work is properly cited.

\section{ABSTRACT}

Background: The objective of this study was to analyze the patterns of labour amongst spontaneous parturients using a WHO modified partogram and compare outcomes of labour and their neonatal outcomes amongst the different partogram patterns

Methods: This prospective study was carried out in the labour room of the department of obstetrics and gynaecology of Acharya Vinoba Bhave rural hospital, Sawangi Meghe, Wardha, Maharashtra, over a period of two years i.e. from October 2012 to September 2014. Analysis of the progress of labour was done in two hundred and fifty women with the help of modified WHO partogram. The patients were divided into three groups. Group A whose partogram remained to the left of the alert line, group B whose partogram remained between the alert and action line and group $\mathrm{C}$ had their partogram crossing the action line. The different types of abnormal labour were studied. The maternal and fetal outcomes were assessed.

Results: $67.2 \%$ of the women belonged to group A, $22.8 \%$ to group B and $10 \%$ to group C. Surgical interference and requirement of augmentation increased as the labour curve moved to the right of the alert line. All patients delivered within 12 hours. Timely intervention reduced the incidence of prolonged labour and its sequelae. 82 patients showed abnormal labour patterns. There were no maternal death or neonatal death.

Conclusions: The use of modified WHO partogram significantly improves both maternal \& neonatal outcome. Routine use of partogram should be implemented in all institutions and all labour rooms in India where delivery care is being given and especially in areas where operative and new-born facilities are lacking to facilitate early referral.

Keywords: Labour, Partogram, Prolonged labor, Alert line, Action line

\section{INTRODUCTION}

"Of the entire journey through our life we make, the most dangerous one remains the first that we take through the birth canal." The care a woman receives during labour should not only help her to cope with stress and pain of labour but also minimize dangers involved. Prolonged labour is associated with several adverse outcomes. It can lead to maternal exhaustion, maternal sepsis, obstructed labour, rupture uterus, postpartum haemorrhage, perinatal asphyxia, neonatal sepsis, disability and can lead to stillbirth, neonatal death and even maternal death. ${ }^{2-4}$
Maternal mortality ratio continues to be the major index of the widening discrepancy in the level of care and the outcome of reproductive health between the advanced and developing countries. It is estimated that for each death of a mother there are 15 who escaped near death by chance. Maternal mortality ratio in India at present is 178 per 100000 live births. ${ }^{5}$ According to the registrar general of India, the millennium development goals of the United nations has set the target of achieving 200 maternal deaths per one lakh live births by 2007 and 109 by 2015 . Obstructed and prolonged labour, haemorrhage, infection features among the five major causes of maternal mortality. Postpartum haemorrhage and postpartum 
sepsis (infection) are very common when the labour gets prolonged beyond 18-24 hours. ${ }^{3}$

The purpose to monitor labour is to recognize incipient problems which may be prevented. Best way to monitor labour is with partogram." A picture is worth a thousand words." 'Partograph' is a Latin/Greek hybrid word, synonymous with Parturition recorded in a graphic form. The partogram includes different variables like fetal heart rate, cervical dilatation, uterine contractions, pulse rate and BP of mother on a pre-printed paper. It allows objective graphic documentation of progress of labour and simplifies clinical interpretation of dynamic changes that occur during labour. Therefore it is a simple tool that is easy to learn and use which saves cost and at the same time helps to improve outcome for the mother and the baby. ${ }^{2,3,6}$

Dr Friedman in 1954 and plotted womens' labour on a graph and defined that all normal labour have a characteristic sigmoid shaped curve and defined various stages of labour and abnormal patterns of labour. ${ }^{7}$ Philpott in 1972 devised a composite labour picture and introduced the alert and action lines to the partogram. ${ }^{6}$ Then WHO in 1994 endorsed the partogram and later modified in 2000 and removed latent phase and defined active phase at 4 centimeters instead of previously used 3 centimeters. WHO advocated its use as a necessary tool in management of labour and recommended its universal use during labour. ${ }^{8}$

We have been confronted with problems of prolonged labour on one side and poor neonatal outcome on the other side. In this study we plan to analyze the patterns of labour amongst spontaneous parturients using a WHO modified partogram and compare outcomes of labour and their neonatal outcomes amongst the different partogram patterns.

\section{METHODS}

This prospective study was conducted in Labour room, Acharya Vinoba Bhave rural hospital, Sawangi Meghe, Wardha, Maharashtra from October 2012 to September 2014. During this study period 130 primigravida and 120 multigravida who fulfilled the inclusion criteria were included in this study.

\section{Inclusion criteria}

- $\quad$ Singleton pregnancies

- After 37 weeks completed weeks

- Spontaneous onset of labour

- Primigravidas and the multigravidas with previous good obstetric history

\section{Exclusion criteria}

Patients with factors such as

\section{Medical complications}

- Severe Pregnancy induced hypertension

- $\quad$ Severe anemia

- Uncontrolled diabetes

Obstetrical complications

- Major degrees of cephalopelvic disproportion

- Contracted pelvis

- Malpresentation

- $\quad$ Post caesarean pregnancy

- Multiple pregnancy

- Preterm labour

- Ante partum haemorrhage

- Intra uterine death

Detailed history regarding age, parity, duration of pregnancy and labour pain was taken from every patient. Examination was done including general physical examination, abdominal examination for fundal height, lie, presentation, engagement, amount of liquor, palpable uterine contraction and fetal heart rate. Pelvic examination was done for pelvic assessment and Bishop score. All the data were entered in a predesigned pro forma. The course of labour in all the patients were recorded on WHO modified partograph. Individual partograph was studied to know the various aspects related to the course of labour and the role of partograph in influencing decision making in abnormal progress of labour was assessed. The graphs of the patients analyzed and were placed in one of the three categories:

- Group A - Patients who delivered when partogram was on or before the alert line

- Group B - Patients who delivered when the partogram crossed alert line but not action line.

- Group C - Patients who delivered when the partogram crossed action line.

The mode of delivery was ascertained and perinatal outcome analyzed by studying condition of baby at birth, APGAR score and neonatal response. Standard statistical 
tests (chi square, unpaired t test, analysis of variance etc.) were used where ever applicable. Significance was assessed at $5 \%$ level of significance.

\section{RESULTS}

Out of 250 patients, majority 218 (87.2\%) were aged between 20-29 years. The mean age of the patients was $24.3 \pm 3.4$ (range: 18-37) years. Primigravidas were predominant in age group less than 24 years while multigravidas predominated after 25 years.

Table 1: Mode of delivery.

\begin{tabular}{|lll|}
\hline Mode of delivery & Frequency & Percentage \\
\hline Spontaneous vaginal delivery & 181 & $72.4 \%$ \\
\hline Assisted delivery forceps & 6 & $2.4 \%$ \\
\hline Assisted delivery vacuum & 4 & $1.6 \%$ \\
\hline LSCS & 59 & $23.6 \%$ \\
\hline Total & 250 & $100.0 \%$ \\
\hline
\end{tabular}

There was no statistically significant association between the partogram and the age and parity of the patients.

Table 1 showed majority $181(72.4 \%)$ delivered vaginally followed by LSCS 59 (23.6\%), 6 (2.4\%) were forceps assisted delivery, while 4 (1.6\%) needed vacuum.

Table 2: Distribution of cases in relation to their partogram pattern.

\begin{tabular}{|lll|}
\hline Partogram & Frequency & Percentage \\
\hline Group A & 168 & $67.2 \%$ \\
\hline Group B & 57 & $22.8 \%$ \\
\hline Group C & 25 & $10.0 \%$ \\
\hline
\end{tabular}

Table 2 showed most of the women delivered when partogram was within alert line (Group A) in 168 (67.2\%) of the patients and when partogram was between alert and action lines (Group B) in $57(22.8 \%)$ patients. The rest $25(10.0 \%)$ delivered when partogram crossed action line (Group C).

Table 3: Distribution of mode of delivery in relation to various abnormal labour patterns.

\begin{tabular}{|lllll|}
\hline $\begin{array}{l}\text { Abnormal labour } \\
\text { patterns }\end{array}$ & $\begin{array}{l}\text { Mode of delivery } \\
\begin{array}{l}\text { Spontaneous } \\
\text { vaginal } \\
\text { delivery }\end{array}\end{array}$ & $\begin{array}{l}\text { Assisted } \\
\text { vaginal } \\
\text { delivery }\end{array}$ & LSCS & Total \\
\hline Failure of descent & 0 & 0 & $1(3 \%)$ & $1(1.3 \%)$ \\
\hline Arrest of descent & 0 & $2(22.2 \%)$ & $4(10.2 \%)$ & $6(7.3 \%)$ \\
\hline Protracted descent & $8(23.5 \%)$ & $7(77.8 \%)$ & $5(13 \%)$ & $20(24.3 \%)$ \\
\hline Arrest of dilatation & 0 & 0 & $9(23 \%)$ & $9(11 \%)$ \\
\hline Protracted dilatation & $26(76.5 \%)$ & 0 & $20(51 \%)$ & $46(56 \%)$ \\
\hline Total & $34(100 \%)$ & $9(100 \%)$ & $39(100 \%)$ & $82(100 \%)$ \\
\hline
\end{tabular}

Table 3 showed out of 82 patients with labour abnormalities, 34 delivered vaginally, 9 required assisted vaginal delivery and 39 underwent LSCS. Of the 34 patients, who delivered vaginally $26(76.5 \%)$ had protracted dilatation and $8(23.5 \%)$ had protracted descent. Of the 6 patients who required assisted vaginal delivery, 2 (22.2\%) had arrest of descent, 7 (77.8\%) had protracted descent. Of the 27 patients who underwent LSCS, $20(51 \%)$ had protracted dilatation, 9 (23\%) had arrest of dilatation $4(10.2 \%)$ had arrest of descent and 5 (13\%) had protracted descent and $1(3 \%)$ had failure of descent.

Table 4: Mode of delivery in relation to partogram pattern.

\begin{tabular}{|lllll|}
\hline Type of delivery & $\begin{array}{l}\text { Partogram } \\
\text { Group A }\end{array}$ & Group B & Group C & Total \\
\hline Spontaneous vaginal delivery & $147(87.5 \%)$ & $29(50.9 \%)$ & $5(20.0 \%)$ & $181(72.4 \%)$ \\
\hline Assisted delivery forceps & $1(0.6 \%)$ & $5(8.8 \%)$ & $0(0.0 \%)$ & $6(2.4 \%)$ \\
\hline Assisted delivery vacuum & $0(0.0 \%)$ & $1(1.8 \%)$ & $3(12.0 \%)$ & $4(1.6 \%)$ \\
\hline LSCS & $20(11.9 \%)$ & $22(38.6 \%)$ & $17(68.0 \%)$ & $59(23.6 \%)$ \\
\hline Total & $168(100.0 \%)$ & $57(100.0 \%)$ & $25(100.0 \%)$ & $250(100.0 \%)$ \\
\hline & P value: 0.001 & Chi square $=86.590$ & \\
\hline
\end{tabular}


Table 4 showed there was significant association of mode of delivery and partogram. The proportion of LSCS was higher in group $\mathrm{C}$ than in group $\mathrm{B}$ and $\mathrm{A}$ in both primigravidas and multigravidas. Vaginal delivery was the highest in group A followed by group B and C in both primigravidas and multigravidas. LSCS was required in
$17(68.0 \%)$ patients in group C and $22(38.6 \%)$ and 20 $(11.9 \%)$ in group B and group A respectively. Vaginal delivery occurred in $147(87.5 \%)$ patients in group A, 29 $(50.9 \%)$ in group B and $5(20.0 \%)$ in group C. Forceps was used in $1(0.6 \%)$ in group A and $5(8.8 \%)$ in group B. vaccum was used in $1(1.8 \%)$ in group B and $3(12 \%)$ in group C.

Table 5: Augmentation of labour in relation to partogram pattern.

\begin{tabular}{|lllll|}
\hline Augmentation & $\begin{array}{l}\text { Partogram } \\
\text { Group A }\end{array}$ & Group B & Group C & Total \\
\hline No & $124(73.8 \%)$ & $18(31.6 \%)$ & $1(4.0 \%)$ & $143(57.2 \%)$ \\
\hline Yes & $44(26.2 \%)$ & $39(68.4 \%)$ & $24(96.0 \%)$ & $107(42.8 \%)$ \\
\hline Total & $168(100.0 \%)$ & $57(100.0 \%)$ & $25(100.0 \%)$ & $250(100.0 \%)$ \\
\hline & P value: 0.001 & Chi square: 63.117 & \\
\hline
\end{tabular}

Table 5 showed the number of deliveries requiring augmentation with ARM and oxytocin among group C were $24(96 \%)$, group B were $39(68.4 \%)$ and group A were $44(26.2 \%)$. Therefore there were more number of deliveries requiring augmentation among group $\mathrm{C}$, followed by group B then group A.

Table 6: Indications for instrumental deliveries and LSCS and partogram pattern.

\begin{tabular}{|lllll|}
\hline \multirow{2}{*}{ Indications } & Partogram & & \\
& Group A & Group B & Group C & Total \\
\hline Fetal Distress & $21(100 \%)$ & $12(42.8 \%)$ & $4(20 \%)$ & $37(53.6 \%)$ \\
\hline Arrest of descent & $0 \%$ & $4(14.2 \%)$ & $2(10 \%)$ & $6(8.7 \%)$ \\
\hline Protracted descent & $0 \%$ & $4(14.2 \%)$ & $4(20 \%)$ & $8(11.6 \%)$ \\
\hline Failure of descent & $0 \%$ & $0 \%$ & $1(5 \%)$ & $1(1.4 \%)$ \\
\hline Arrest of dilatation & $0 \%$ & $5(18 \%)$ & $4(20 \%)$ & $9(13 \%)$ \\
\hline Protracted dilatation & $0 \%$ & $3(10.8 \%)$ & $5(25 \%)$ & $8(11.6 \%)$ \\
\hline Total & $21(100 \%)$ & $28(100 \%)$ & $20(100 \%)$ & $69(100 \%)$ \\
\hline & P value: 0.001 & \multicolumn{2}{c}{ Chi square: 31.927} \\
\hline
\end{tabular}

Table 6 showed in the sub analysis of the 59 LSCS cases and 10 instrumental cases done for indications, there were total $37(53.6 \%)$ cases of fetal distress and remaining $34(46.4 \%)$ were various labour abnormalities. In group A all the $21(100 \%)$ patients had fetal distress. In group B out of 28 patients, $12(42.8 \%)$ were for fetal distress, $4(14.2 \%)$ for both arrest of descent and protracted descent, $3(10.8 \%)$ for protracted dilatation, 5 (18\%) for arrest of dilatation. In Group $\mathrm{C}$ out of 20 patients, $4(20 \%)$ were for fetal distress, 2(10\%) for arrest of descent, $4(20 \%)$ for protracted descent, $1(5 \%)$ for failure of descent, 5 (25\%) for protracted dilatation and 4 (20\%) for arrest of dilatation. Therefore the indications were different between the partogram groups and significantly associated.

The mean duration of $1^{\text {st }}$ stage of labour was more in group C (8.7 hours) compared to group A (4.2 hours) and group B (6.4 hours). The duration was almost double in women who crossed action line (group C) than women who delivered within alert line (group A). Labour was completed within 12 hours in all patients. The least dilatation rate was observed in cases that were in group $\mathrm{C}$ $(0.9 \mathrm{~cm} /$ hour $)$ followed by group $\mathrm{B}(1.2 \mathrm{~cm} /$ hour $)$ and group A (1.6 cm/hour). The mean duration was not statistically significant between the three groups in $2^{\text {nd }}$ stage of labour.

The average birth weight of the neonates was $2.6 \pm 0.3$, $2.7 \pm 0.3$ and $2.7 \pm 0.3 \mathrm{~kg}$ in groups $\mathrm{A}, \mathrm{B}$ and $\mathrm{C}$, respectively. The difference of mean birth weight between the three partogram groups was not statistically significant.

The majority of neonates in all the three partogram groups had $\mathrm{APGAR} \geq 7$ at $1 \mathrm{~min}$ and also 5 minutes. 
APGAR $<7$ at 1 min was seen in $5(20 \%)$ in group C, 7 $(12.2 \%)$ in group B and $7(4 \%)$ in group $\mathrm{A}$ and at 5 minutes was seen in $2(8 \%)$ in group C, $3(5.2 \%)$ in group $\mathrm{B}$ and $2(1.2 \%)$ neonates in group $\mathrm{A}$.

Table 7: Neonatal Response in relation to partogram pattern.

\begin{tabular}{|lllll|}
\hline Neonatal Response & $\begin{array}{l}\text { Partogram } \\
\text { Group A }\end{array}$ & Group B & Group C & Total \\
\hline Spontaneous cry & $161(95.8 \%)$ & $50(87.8 \%)$ & $20(80 \%)$ & $231(92.4 \%)$ \\
\hline Cry after resuscitation (CR) & $5(3 \%)$ & $4(7 \%)$ & $3(12 \%)$ & $12(4.8 \%)$ \\
\hline NICU & $2(1.2 \%)$ & $3(5.2 \%)$ & $2(8 \%)$ & $7(2.8 \%)$ \\
\hline Total & $168(100.0 \%)$ & $57(100.0 \%)$ & $25(100.0 \%)$ & $250(100.0 \%)$ \\
\hline \multicolumn{5}{l}{} \\
\hline
\end{tabular}

The neonatal response was significantly different between the three partogram groups Spontaneous cry was the response in majority of neonates in all the three groups. NICU care and cry after resuscitation were proportionately more in group $\mathrm{B}$ and $\mathrm{C}$ than in group $\mathrm{A}$. NICU care was required in $3(5.2 \%)$ of the neonates in the group B and $2(8.0 \%)$ in group C and in $2(1.2 \%)$ neonates of group A. Cry after resuscitation was seen in 3 (120\%) neonates of Group C and 4 (7\%) and $5(3 \%)$ in group B and group A respectively.

The babies who cried after resuscitation were in NICU for few hours for observation and the babies who required NICU care were shifted to mother's side within 4 days. There were no neonatal deaths.

The difference in the maternal complication rates was significantly different between the three groups. The complication rate among the group $\mathrm{A}$ was $1.2 \%$ compared to $3.6 \%$ in group B and $16.0 \%$ in Group C. The complications were one $\mathrm{PPH}$ in group $\mathrm{C}$, Puerperal pyrexia (2 each in group B and A, 3 in group C). There were no maternal deaths.

\section{DISCUSSION}

Although labour is a natural phenomenon leading to the child birth and most of them do occur spontaneously, a few tend to become dystonic and result in prolonged labour. Hence it is essential to identify the abnormality early and deliver them safely in time by appropriate intervention.

E.A, Friedman in 1954 following a study on a large number of women in the USA, described a normal cervical dilatation pattern. ${ }^{7}$

In 1969 Hendricks et al. demonstrated that in the active phase of normal labour the rate of dilatation of the cervix in primigravidas and multigravidas varies little and that there is no deceleration phase at the end of the first stage of labour. 9
Philpott in extensive studies of primigravidas in Central and Southern Africa constructed a partogram for cervical dilation in his population and was able to identify deviations from the normal and provide a sound scientific basis for early intervention leading to the prevention of prolonged labour. $^{6}$

In 1973 John Studd constructed "Labour stencils" or "Normogram" for the purpose of forecasting the expected pattern of progression according to the degree of dilatation achieved at the time of admission and showed that the partogram can separate normal labour from labour destined to result in an abnormal outcome. ${ }^{10}$

Since then various authors have developed similar partograms and brought about various modifications. The WHO model of the partograph has been devised by an Informal Working Group which examined most of the available published work on partographs and their design. It represents a synthesized and simplified format including the best features of several partographs. ${ }^{8}$

Since then many obstetricians started using this concept as an aid to intrapartum management and various studies have been conducted by a number of researchers.

This prospective study was conducted on 250 term primigravida and multigravida during period of two years (from 2012-2014) labour progress and their outcomes were analyzed by means of modified WHO partogram at the labour room, Department of Obstetrics and Gynecology, Sawangi Meghe,Wardha, Maharashtra.

In this study age and parity had no association with partogram pattern. Majority of patients delivered vaginally followed by LSCS and instrumental delivery. Most of the women delivered when partogram was within alert line (Group A) followed by group B, when partogram was between alert and action lines and group $\mathrm{C}$, when partogram crossed action line. The distribution of patients in relation to partogram pattern was comparable to other studies as shown in the Table below. 
Table 8: Distribution of patients in relation to partogram pattern in different studies.

\begin{tabular}{|lllllll|}
\begin{tabular}{|l} 
Partogram \\
group
\end{tabular} & $\begin{array}{l}\text { Philpott and } \\
\text { Castle et al. } \\
(\mathbf{1 9 7 2})\end{array}$ & $\begin{array}{l}\text { Daftary and } \\
\text { Mhatre }^{11} \\
(\mathbf{1 9 7 7})\end{array}$ & $\begin{array}{l}\text { Sharmin } \\
\text { et al. }^{12} \\
(\mathbf{2 0 0 5})\end{array}$ & $\begin{array}{l}\text { Ernest Orji } \\
\text { et al. }^{14}(\mathbf{2 0 0 6})\end{array}$ & $\begin{array}{l}\text { Lakshmidevi } \\
\text { et al. }{ }^{13}(\mathbf{2 0 1 1})\end{array}$ & $\begin{array}{l}\text { Sanyal } \\
\text { et al. }^{15} \\
(\mathbf{2 0 1 2})\end{array}$ \\
\hline $\mathbf{A}$ & $\mathbf{7 8 \%}$ & $66 \%$ & $68.5 \%$ & $55.1 \%$ & $66.5 \%$ & $80.8 \%$ \\
\hline $\mathbf{B}$ & $11 \%$ & $25.5 \%$ & $27 \%$ & $27.9 \%$ & $20 \%$ & $15.2 \%$ \\
\hline $\mathbf{C}$ & $11 \%$ & $8.5 \%$ & $4.5 \%$ & $16.9 \%$ & $13.5 \%$ & $4 \%$ \\
\hline
\end{tabular}

Table 9: Mode of delivery in relation to partogram pattern in different studies.

\begin{tabular}{|c|c|c|c|c|c|c|c|c|c|c|c|c|c|c|c|}
\hline \multirow[b]{2}{*}{$\begin{array}{l}\text { Partogram } \\
\text { group }\end{array}$} & \multicolumn{3}{|c|}{$\begin{array}{l}\text { Philpott and castle } \\
\text { et al. }{ }^{6}\end{array}$} & \multicolumn{3}{|c|}{ Daftary and Mhatre ${ }^{11}$} & \multicolumn{3}{|c|}{ Sharmin et al. ${ }^{12}$} & \multicolumn{3}{|c|}{ Lakshmidevi et al. ${ }^{13}$} & \multicolumn{3}{|c|}{ Present study } \\
\hline & $\underset{\mathbf{Z}}{\mathrm{Z}}$ & 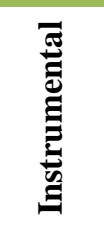 & ల్ల & $\underset{Z}{Z}$ & & $\underbrace{n}_{n=1}$ & $\underset{\mathrm{Z}}{\mathrm{Z}}$ & & ల్ & $\underset{\mathbf{Z}}{\mathrm{Z}}$ & & ల్ల & $\underset{\mathbf{Z}}{\mathrm{Z}}$ & 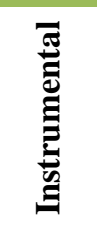 & ల్ల \\
\hline A & 89.76 & 9.8 & 0.4 & 85.61 & & & & 7.9 & & & & & 27 & 0.6 & 11.9 \\
\hline B & 79.41 & 20.95 & & & 33.3 & & & 8.9 & & & 0 & & & 10.6 & 38.6 \\
\hline $\mathrm{C}$ & & & 100 & 5.8 & & 76.48 & & & 100 & 18.5 & 55.6 & 2.59 & 20 & 12 & 68 \\
\hline
\end{tabular}

In this study patient in group A had a high likelihood of spontaneous vaginal delivery in both primigravidas and multigravidas. There were more number of deliveries which required augmentation and more LSCS and instrumental deliveries as the partogram crossed to the right of alert and action lines in both primigravidas and multigravidas.

Although a patient in group B required intensive monitoring and active management of labour, the likelihood of FTND was still high in both primigravidas and multigravidas.

The findings were significantly different among the groups and were comparable to studies by other authors. So when we plot progress of labour on partogram we can predict outcome of labour.

In this study of all the labour abnormalities observed in Group B and Group C, dilatational abnormalities were more common than descent abnormalities.

All patients delivered with 12 hours of onset of labour. The indications for LSCS and instrumental deliveries were different between the Partogram groups. All were for fetal distress in group $\mathrm{A}$ and there were more incidence of labour abnormalities in Group B and Group C.

In similar study by Laksmidevi et al., ${ }^{13} 2011$ on 200 primigravidas, fetal distress was main indicator in group A \& B (100\%) and lack of progress for group C (60\%), rest were fetal distress in group $\mathrm{C}$.
Table 10: Cervical dilatation rate in relation to partogram pattern in different studies.

\begin{tabular}{|c|c|c|c|}
\hline $\begin{array}{l}\text { Cervical } \\
\text { dilatation rate } \\
(\mathrm{cm} / \mathrm{hour})\end{array}$ & $\begin{array}{l}\text { Philpott } \\
\text { \& Castle }{ }^{6} \\
(1972)\end{array}$ & $\begin{array}{l}\text { Laksmidevi } \\
\text { et al. }{ }^{13} \\
(2011)\end{array}$ & $\begin{array}{l}\text { Present } \\
\text { study }\end{array}$ \\
\hline Group A & 1.68 & 1.4 & 1.6 \\
\hline Group B & 0.86 & 0.8 & 1.2 \\
\hline Group C & 0.18 & 0.6 & 0.9 \\
\hline
\end{tabular}

In this study duration of active phase of labour and rate of cervical dilatation was the main factor affecting progress of labour and shifting curve to right side. The least dilatation rate was observed in cases that were in group $\mathrm{C}$ $(0.9 \mathrm{~cm} /$ hour $)$ followed by group $\mathrm{B}(1.2 \mathrm{~cm} /$ hour $)$ and group A (1.6 cm/hour). The mean duration of $1^{\text {st }}$ stage of labour and partogram was almost double in women who crossed action line than women who delivered within alert line. The mean duration was not different between the three groups in $2^{\text {nd }}$ Stage of labour.

There was no difference of mean birth weight between the three partogram groups. APGAR $<7$ and cry after resuscitation were proportionately more in Group B and $\mathrm{C}$ than in group A. Most babies (92.4\%) in all three groups had spontaneous cry and APGAR $\geq 7$ at 1 minute and 5 minute. There were no neonatal deaths. In a similar study by Sharmin et al., ${ }^{12} 2005$ on 232 patients NICU care was required in 7 (3\%) of the infants, cry after resuscitation was seen in $30(12.9 \%)$ neonates, Spontaneous cry seen in $195(84.1 \%)$. There were no maternal deaths or any major maternal morbidities in this study. So, by plotting partogram neonatal outcome can be predicted and maternal complications can be reduced. 


\section{CONCLUSION}

\section{The study helped us come to the following conclusions}

1. Abnormal labour patterns can be identified earlier by partogram.

2. The difference in outcomes like mode of delivery, augmentation of labour and neonatal outcome was significant and can be predicted by partogram.

3. Maternal and perinatal outcomes can be predicted with use of partogram.

Hence partographic analysis of labour provides valuable information on the progress of labour and it permits early corrective therapy and also helps us in predicting outcomes during the labour and hence the partogram can be highly effective in reducing complications from prolonged labour for both the mother and the neonate and also improving neonatal outcome. It is useful in settings with poorer access to health care resources. Hence in our country where rural population is still predominant training the nurses, ANM and other staff in primary health centers would help in detecting labour abnormalities earlier and their early referral to tertiary centre as we are yet to achieve effective peripheral level emergency obstetric care to prevent complications and reduce neonatal and maternal morbidity and mortality. So reutilization of partogram can play an important role in helping to achieve the MDG.

The word obstetrics can be better interpreted as 'obs stare' meaning "I stand by" which indicates the role of the obstetrician which would not be complete without intelligent interpretation and methodical monitoring. Therefore it can be better addressed as watchful expectancy with the need to intervene when the circumstances necessitate. Thus we can say that partogram is a simple, economical, time saving and effective tool for the obstetrician to identify vagaries of labour at right time and prevent the consequences to take an obtuse turn. Routine use of partogram should be implemented in all institutions and all labour rooms in India where delivery care is being given and especially in areas where operative and new-born facilities are lacking to facilitate early referral. Our study has shown that though the partogram is an old tool it still remains gold standard even for modern obstetric care.

Funding: No funding sources Conflict of interest: None declared

Ethical approval: The study was approved by the institutional ethics committee

\section{REFERENCES}

1. Mishra R. Management of labour. In: Mishra R, eds. Practical Obstetric Problems. 6th ed. UK: Ian Donald; 2007: 506-521.

2. Iffat Javed, Shereen Bhutta, Tabassum Shoaib. Role of partogram in preventing prolonged labour. J Pak Med Assoc. 2007 Aug;57(8):408-11.

3. Neilson JP, Lavender T, Quenby S. Obstructed labour Reducing maternal death and disability during pregnancy. Br Med Bull. 2003;67(1):191-204.

4. Surekha Tayade, Pooja Jadhao. The impact of use of modified who partograph on maternal and perinatal outcome. IJBAR. 2012;03(04):256-62.

5. WHO, UNICEF, UNFPA, the World Bank. Trends in maternal mortality: 1990 to 2013. In: WHO, eds. Sexual and Reproductive Health. Geneva: WHO; 2014: $1-56$.

6. Philpott RH. Graphic records in labor. Br Med J. 1972;4:163.

7. Friedman EA. Evolution of graphic analysis of labor. Am J Obstet Gynaecol. 1978 Dec;132(7):824.

8. World Health Organization. The partograph. A Managerial tool for the prevention of prolonged labour. In: WHO, eds. Section 1: The Principle and Strategy. WHO Document Number: WHO/MCH/88.3. Geneva: WHO; 1988.

9. Hendricks $\mathrm{CH}$, Brenner WE. Normal cervical dilatation pattern in late pregnancy and labor. Am $\mathbf{J}$ Obstet Gynaecol. 1970;10:1065.

10. John Studd. Partograms and normograms of cervical dilatation in management of primigravida labor. $\mathrm{Br}$ Med J. 1973 Nov;4(5890):451-5.

11. Daftary SN, Mhatre PN. Cervicograph in the management of labour in primigravidas. J Obstet Gynaecol. 1997;27:687-91.

12. Sharmin S, Rashid M, Hazra SC, Khondker L. Implementation of partograph and its effect on outcome of spontaneous labour at term. Bangladesh Med J. 2012;41(1):42-4.

13. Lakshmidevi Muralidhar, Malini KV. Partographic analysis of spontaneous labour at term in primigravida; Shetty Vishma. J Obstet Gynaecol India. 2012 Nov-Dec;62(6):635-40.

14. Orji E. Evaluating progress of labor in nulliparas and multiparas using the modified WHO partograph. Int J Gynaecol Obstet. 2008;102(3):249-52.

15. Sanyal U, Goswami S, Mukhopadhyay P. The role of partograph in the outcome of spontaneous labour. NJOG. 2014 Jan-Jun;17(1):52-7.

DOI: $10.5455 / 2320-1770 . i j r \operatorname{cog} 20141233$

Cite this article as: Penumadu KM, Hariharan C.

Role of partogram in the management of spontaneous labour in primigravida and multigravida. Int $\mathrm{J}$ Reprod Contracept Obstet Gynecol 2014;3:1043-9. 